\title{
Studies of the Chronological Course of Wisdom Tooth Eruption in a Black African Population
}

- $\quad$ Andreas Olze ${ }^{1}$ Ph.D.;

- $\quad$ Piet van Niekerk ${ }^{2}$ L.D.S.;

- $\quad$ Ronald Schulz, ${ }^{3}$ M.D.; and

- $\quad$ Andreas Schmeling ${ }^{3}$ Ph.D.

${ }^{1}$ Institut für Rechtsmedizin, Charité - Universitätsmedizin Berlin, Turmstrasse 21, 10559

Berlin, Germany.

${ }^{2}$ Department of Oral Pathology and Oral Biology, University of Pretoria, P.O. Box 1266, Pretoria 0001, South Africa.

${ }^{3}$ Institut für Rechtsmedizin, Röntgenstrasse 23, 48149 Münster, Germany.

Additional information and reprint requests:

Andreas Schmeling, Ph.D.

Institut für Rechtsmedizin

Röntgenstrasse 23

48149 Münster

Germany

E-mail: andreas.schmeling@ukmuenster.de

[Figure and tables at the bottom of the document]

\section{Abstract}

The importance of forensic age estimation in living subjects has grown over the last few years. In dental age estimation, tooth eruption is a parameter of developmental 
morphology that can be analyzed by either clinical examination or by evaluation of dental $\mathrm{X}$-rays. In the present study, we determined the stage of wisdom tooth eruption in 410 male and 106 female Black South African subjects of known age (12-26 years) based on radiological evidence from 516 conventional orthopantomograms. Four eruption stages were determined (no emergence, alveolar emergence, gingival emergence, complete emergence). Statistical scores were determined for the individual stages separately for both sexes. The data presented here can be utilized for forensic estimation of the minimum and most probable ages of investigated persons.

The international and interdisciplinary Study Group on Forensic Age Diagnostics (http://rechtsmedizin.klinikum.uni-muenster.de/agfad/index.htm) published recommendations for forensic age assessment in living subjects undergoing criminal investigation. The reason for the increasing importance of age assessment in living subjects is the growing number of foreign nationals without valid identification papers and, consequently, the growing number of subjects of unconfirmed age whose chronological age is relevant in legal proceedings. In Germany, the ages of 14, 16, 18, and 21 are of legal relevance (1). In many other European countries, the age of legal majority also ranges from 14 to 18 (2).

Tooth eruption is a parameter of developmental morphology which, unlike tooth mineralization, can be determined in two ways: by clinical examination and/or by evaluation of dental X-rays. In the cases of teeth 1 to 7 , there is sufficient data on the emergence sequences of the permanent dentition to obtain reliable forensic age estimations in children and early adolescents (3).

In the present study, the chronological course of third molar eruption will be analyzed based on evidence from conventional orthopantomograms obtained in a Black South African population. Based on these findings, the suitability of the age of third molar eruption as a parameter for forensic age assessment in living subjects will be assessed.

\section{Materials and Methods}

A total of 516 conventional orthopantomograms from 410 male and 106 female Black South African subjects of known age (12-26 years) were analyzed. The age and sex distribution of the study population is shown in Table 1 . The investigated radiographs 
were obtained from the files of the Department of Oral Pathology and Oral Biology of the University of Pretoria. The orthopantomograms were made during the years 1992-2002. The patient identification number, sex, date of birth, date of X-ray, and eruption stages of the wisdom teeth were recorded for each proband. Each proband's age was calculated as the date of X-ray minus the date of birth. The appropriate ethics commission gave its consent to the project.

The following staging system was used for classification of third molar eruption (Fig. 1): Stage A Occlusal plane covered with alveolar bone.

Stage B Alveolar emergence; complete resorption of alveolar bone over occlusal plane.

Stage C Gingival emergence; penetration of gingiva by at least one dental cusp.

Stage D Complete emergence in occlusal plane.

Impacted wisdom teeth were excluded from the analysis. Mesially, distally and vestibuloorally angulated third molars were classified as impacted as recommended by Archer (4) and Wolf and Haunfelder (므). Wisdom teeth with an unclear direction of emergence also were not included in the analysis. All staging was carried out by the same observer (A.O.). The observer is a dentist and has long experience in the field of forensic age diagnostics.

Statistical analyses were performed using SPSS software (Version 11.0, SPSS Inc., Chicago, IL). To cope with outliers and/or skew distributions, differences between groups of interest were analyzed using nonparametric tests (Kruskal-Wallis test for multiple groups, Mann-Whitney $U$-test for two independent groups, and Wilcoxon test for paired observations). Exact versions of the tests were used to handle major differences in sample sizes. The level of significance was defined as $p<0.05$ (two-sided tables). Intra-observer agreement was determined on an independent sample of 100 orthopantomograms using the kappa coefficient. The interval between the observations was 6 months. 


\section{Results}

Tables 2 and 3 show the number of cases, minimum, maximum and mean values with standard deviation ranges, and median values with lower and upper quartiles for the age of eruption of teeth $18,28,38$, and 48 according to eruption stage for males and females, respectively. In the case of stage $\mathrm{D}$, the age of $50 \%$ frequency was additionally calculated (see Table 4).

The minimum age of alveolar emergence of the wisdom teeth ranged from 12.1 to 13.8 years in females and from 12.8 to 15.4 years in males. The mean age of alveolar emergence ranged from 15.1 to 18.0 years in women and from 17.2 to 19.1 years in men. The corresponding standard deviation ranges were 2.0-3.4 and 1.9-4.0 years, respectively.

The minimum age of gingival emergence in our study population ranged from 14.5 to 16.3 years in females and from 16.0 to 18.4 years in males. The most probable age of gingival emergence ranged from 18.7 to 19.9 years in women and from 20.7 to 21.0 years in men. The corresponding standard deviation ranges were 1.6-5.4 and 2.4-2.9 years, respectively.

The minimum age of complete emergence of the wisdom teeth in the occlusal plane was 16.1 years in females and 16.7-17.0 years in males. The most probable age for complete emergence was calculated based on the age of 50\% frequency, which was 16-19 years for both males and females in our study population.

Statistically significant sex differences were only observed for tooth 48 at eruption stages A and B. However, the low number of cases must be noted.

The kappa coefficients for the intra-observer agreement were between 0.88 and 0.96 .

\section{Discussion}

Studies on the chronology of wisdom tooth eruption are scarce. The third molars do not emerge before the 17th year of life in European populations $(6,7)$ but may emerge as early as age 13 in other populations, according to reports by Shouri (8), Chagula (9), and Otuyemi et al. (10). 
Shouri (8) investigated eruption of the permanent teeth in 1412 boys and 474 girls from a southern Indian region (Madras) and 1713 boys from the northern Indian region around Lahore; the subjects' ages ranged from 6 to 21 years. One to three percent of the south Indian boys' upper and lower wisdom teeth started to emerge at the age of 13 years. At least one third molar had erupted in $4 \%$ of the south Indian girls by the age of 13 . Furthermore, $0.5-0.7 \%$ of the north Indian boys exhibited the emergence of at least one wisdom tooth at age 13 .

Chagula (9) studied wisdom tooth eruption in 990 Black Ugandan males aged 6-26 years. Eruption of at least one wisdom tooth was detected in $10 \%$ of the investigated 13-yearolds. All four wisdom teeth were present in the oral cavity in $9 \%$ of all 14-year-olds studied.

Otuyemi et al. (10) investigated eruption of the third molars in 523 male and 548 female Black Nigerians aged 11-21 years. Wisdom tooth eruption started at the age of 14 in males and at age 13 in females. Emergence of all four wisdom teeth in the oral cavity was observed in 1.1 percent of the study population at this age. For the overall population, the mean age ( \pm standard deviation) at which 1,2 , or 3 wisdom teeth had emerged was $16.6 \pm 1.7$ years, and the mean age of emergence of all four wisdom teeth was $17.5 \pm 1.6$ years. Divided by gender, the mean age of emergence of all four third molars was $17.4 \pm 1.6$ years in the male subjects and $17.1 \pm 1.6$ years in the females.

The results of the cited studies cannot be used for age assessment in a court of law because the age of a number of probands could not be confirmed.

Our findings make it possible to estimate the age of investigated persons based on alveolar, gingival, and complete emergence of the third molars in the occlusal plane and permit an estimation of the minimum and most probable age of such individuals in the scope of forensic age assessments.

\section{References}

1. Kaatsch HJ. Juristische Aspekte der Altersschätzung. In: Oehmichen M, Geserick G, editors. Osteologische identifikation und altersschätzung. Lübeck: Schmidt- Römhild, 2001;243-54. 
2.

Dünkel F, Van Kalmthout A, Schüler-Springorum H. Entwicklungstendenzen und Reformstrategien im jugendstrafrecht im europäischen Vergleich. Mönchengladbach:

Forum, 1997.

3.

Wedl JS, Stiefel BG, Friedrich RE, Dietz K, Schmelzle R. Inspektorische Beurteilung des Durchbruchs der Bleibenden Zähne bei Kindern und Jugendlichen als Forensischodontologisches Hilfsmittel zur Bestimmung des chronologischen alters. Rechtsmed 2002;12:87-99.

4.

Archer WH. Die chirurgie des Mundes und der Zähne. Stuttgart: Medica, 1955.

5.

Wolf H, Haunfelder D. Zahnärztliche Mundchirurgie für Studierende der Zahnheilkunde. Berlin: Berlinische Verlagsanstalt, 1960;5:59-67

6.

Rantanen AV. The age of eruption of the third molar teeth. Acta Odontol Scand 1967;25(Suppl.):1-86.

7.

Müller HR. Eine Studie über die IInkonstanz des dritten Molaren (Fehlen, Anlage, Durchbruch) [dissertation]. Dresden: Univ. of Dresden, 1983.

8.

Shourie KL. Eruption age of teeth in India. Ind J Med Res 1946;34:105-18.

9.

Chagula WK. The age at eruption of third permanent molars in male East Africans. Am $J$ Phys Anthropol 1960;18:77-82.

10.

Otuyemi OD, Ugboko VI, Ndukwe KC, Adekoya-Sofowora CA. Eruption times of third molars in young rural Nigerians. Int Dent J 1997;47:266-70. 


\section{Figures and Tables}

FIG. 1- Stages a to d of third molar eruption.

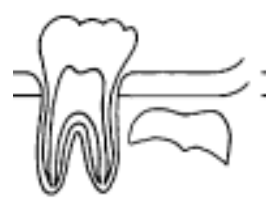

(a)

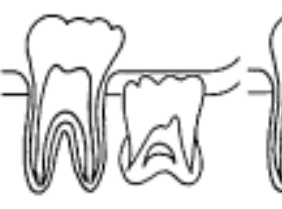

(b)

(c)

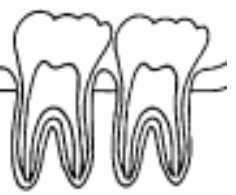

(d)

TABLE 1- Age and sex distribution of the sample.

\begin{tabular}{|l|l|l|}
\hline \multicolumn{1}{|c|}{ Age } & \multicolumn{1}{|c|}{ Male } & \\
\hline 12 & 5 & 3 \\
\hline 13 & 8 & 4 \\
\hline 14 & 3 & 4 \\
\hline 15 & 8 & 5 \\
\hline 16 & 9 & 12 \\
\hline 17 & 15 & 6 \\
\hline 18 & 21 & 7 \\
\hline 19 & 34 & 6 \\
\hline 20 & 37 & 11 \\
\hline 21 & 48 & 9 \\
\hline 22 & 63 & 12 \\
\hline 23 & 55 & 12 \\
\hline 24 & 58 & 7 \\
\hline 25 & 33 & 6 \\
\hline Total & 13 & 106 \\
\hline
\end{tabular}


TABLE 2- Statistical data on the age of emergence of teeth $18,28,38$, and 48 , by stage, in males.

\begin{tabular}{|c|c|c|c|c|c|c|c|c|c|}
\hline Tooth & Stage & $n$ & Min & Max & Mean & SD & LQ & Median & UQ \\
\hline \multirow[t]{4}{*}{18} & A & 18 & 12.0 & 22.4 & 15.7 & 3.5 & 13.0 & 14.6 & 17.6 \\
\hline & B & 44 & 12.8 & 24.3 & 17.8 & 2.8 & 16.2 & 17.7 & 19.3 \\
\hline & C & 24 & 16.0 & 26.8 & 20.7 & 2.5 & 18.6 & 20.5 & 22.6 \\
\hline & D & 284 & 17.0 & 27.0 & 22.7 & 2.1 & 21.3 & 22.8 & 24.3 \\
\hline \multirow[t]{4}{*}{28} & A & 14 & 12.0 & 22.4 & 14.4 & 2.6 & 12.9 & 13.7 & 15.2 \\
\hline & B & 51 & 12.8 & 25.0 & 18.4 & 3.1 & 16.4 & 18.6 & 20.3 \\
\hline & C & 20 & 16.0 & 26.8 & 21.0 & 2.9 & 19.0 & 20.7 & 24.0 \\
\hline & D & 290 & 17.0 & 26.9 & 22.6 & 2.2 & 21.2 & 22.8 & 24.3 \\
\hline \multirow[t]{4}{*}{38} & A & 5 & 12.0 & 15.7 & 13.6 & 1.4 & 12.5 & 13.3 & 14.9 \\
\hline & B & 8 & 15.4 & 26.1 & 19.1 & 4.0 & 15.7 & 17.8 & 22.6 \\
\hline & C & 4 & 18.4 & 24.2 & 20.8 & 2.8 & 18.5 & 20.2 & 23.6 \\
\hline & D & 250 & 16.7 & 26.9 & 22.4 & 2.2 & 20.9 & 22.6 & 24.2 \\
\hline \multirow[t]{4}{*}{48} & A & 9 & 12.0 & 15.7 & 13.6 & 1.3 & 12.6 & 13.5 & 14.7 \\
\hline & B & 13 & 15.1 & 20.3 & 17.2 & 1.9 & 15.4 & 16.4 & 19.2 \\
\hline & C & 7 & 18.4 & 24.2 & 20.7 & 2.4 & 18.6 & 20.8 & 23.4 \\
\hline & D & 256 & 17.0 & 26.9 & 22.6 & 2.2 & 21.1 & 22.8 & 24.2 \\
\hline \multicolumn{10}{|c|}{$\begin{array}{l}\text { n, number of cases; Min, minimum age; Max, maximum age; SD, standard } \\
\text { deviation; LQ, lower quartile; UQ, upper quartile. }\end{array}$} \\
\hline
\end{tabular}


TABLE 3- Statistical data on the age of emergence of teeth 18,28 , 38, and 48 , by stage, in females.

\begin{tabular}{|c|c|c|c|c|c|c|c|c|c|}
\hline Tooth & Stage & $n$ & Min & Max & Mean & SD & LQ & Median & UQ \\
\hline \multirow[t]{4}{*}{18} & A & 15 & 12.1 & 18.9 & 14.8 & 1.9 & 13.0 & 14.9 & 16.0 \\
\hline & B & 16 & 13.8 & 22.9 & 18.0 & 3.0 & 15.4 & 17.2 & 21.3 \\
\hline & C & 6 & 16.3 & 20.7 & 18.7 & 1.6 & 17.2 & 19.2 & 19.7 \\
\hline & $\mathrm{D}$ & 60 & 16.1 & 26.2 & 22.0 & 2.6 & 20.4 & 22.3 & 23.8 \\
\hline \multirow[t]{4}{*}{28} & A & 13 & 12.1 & 18.9 & 15.1 & 2.1 & 13.1 & 15.1 & 16.8 \\
\hline & B & 15 & 13.0 & 23.8 & 17.3 & 3.4 & 14.5 & 16.7 & 20.5 \\
\hline & C & 10 & 16.1 & 25.8 & 19.4 & 3.1 & 16.4 & 19.0 & 21.5 \\
\hline & D & 61 & 16.1 & 26.8 & 22.0 & 2.6 & 20.3 & 22.2 & 23.8 \\
\hline \multirow[t]{4}{*}{38} & A & 2 & 14.9 & 16.0 & 15.4 & 0.8 & 14.9 & 15.4 & 16.0 \\
\hline & B & 11 & 12.1 & 21.9 & 15.7 & 2.7 & 13.8 & 15.5 & 17.2 \\
\hline & C & 3 & 14.5 & 23.8 & 18.6 & 4.7 & 14.5 & 17.6 & 23.8 \\
\hline & D & 58 & 16.1 & 26.8 & 21.7 & 2.8 & 19.8 & 22.2 & 23.7 \\
\hline \multirow[t]{4}{*}{48} & A & 3 & 14.9 & 17.2 & 16.0 & 1.2 & 14.9 & 16.0 & 17.2 \\
\hline & B & 11 & 12.1 & 18.6 & 15.1 & 2.0 & 13.8 & 14.6 & 16.7 \\
\hline & C & 2 & 16.1 & 23.8 & 19.9 & 5.4 & 16.1 & 19.9 & 23.8 \\
\hline & D & 54 & 16.1 & 26.8 & 22.0 & 2.7 & 20.2 & 22.4 & 23.7 \\
\hline \multicolumn{10}{|c|}{$\begin{array}{l}n \text {, number of cases; Min, minimum age; Max, maximum age; SD, standard } \\
\text { deviation; LQ, lower quartile; UQ, upper quartile. }\end{array}$} \\
\hline
\end{tabular}


TABLE 4-Age of 50\% frequency for stage D.

\begin{tabular}{|l|l|l|l|l|}
\hline & \multicolumn{1}{|c|}{ Tooth 18 } & \multicolumn{1}{|c|}{ Tooth 28 } & \multicolumn{1}{|c|}{ Tooth 38 } & \multicolumn{1}{|c|}{ Tooth 48 } \\
\hline Males & $18-19$ & 17 & $16-17$ & 17 \\
\hline Females & 17 & $18-19$ & $17-18$ & 16 \\
\hline
\end{tabular}

